\title{
Construction and Application of Evaluation Index System for New and Old Kinetic Energy Conversion
}

\author{
Wanlei Xue ${ }^{1, \mathrm{a}}$, Yongqi Yang ${ }^{1, \mathrm{~b}}$, Rui Tang ${ }^{2, \mathrm{c}}, \mathrm{Nan} \mathrm{Xu}^{1, \mathrm{~d}}$ and Lili Zhang ${ }^{3, \mathrm{e}, *}$ \\ ${ }^{1}$ Economic and Technology Research Institute, State Grid Shandong Electric Power Company, Jinan, China \\ ${ }^{2}$ Harbin University of Commerce, Harbin, China \\ ${ }^{3}$ State Grid Energy Research Institute Co., Ltd., Beijing, China \\ axwlsea@126.com, byangyongqincepu@163.com, ${ }^{3}$ tr940419@163.com, dxunan0517@163.com, ${ }^{2}$ zhanglili@amss.ac.cn \\ *Corresponding author
}

\begin{abstract}
This document decomposes the connotation and goals of the old and new kinetic energy transformation into seven dimensions: development effectiveness, innovation development, openness, environmental protection and people's livelihood, etc. Then, through the analytic hierarchy process and comprehensive evaluation method, the evaluation index system of new and old kinetic energy conversion is constructed. And we quantitatively evaluate the effectiveness in Shandong Province. Compared with the effects in the advanced areas of the east and the backward areas of the central and western regions, we find that in terms of openness, environmental protection, people's livelihood development and digital economy development, Shandong Province has a large gap with Guangdong, Jiangsu, and Zhejiang, and even lower than the backward provinces such as Anhui and Henan; in terms of development effectiveness, innovation development and factor supply, the gap between Shandong, Guangdong, Jiangsu and Zhejiang is relatively small, but there is no significant advantage compared with the backward provinces such as Anhui and Henan; in terms of system supply, Shandong and Guangdong, Jiangsu, Zhejiang are similar.
\end{abstract}

Keywords: new and old kinetic energy conversion, evaluation index system, entropy weight method

\section{INTRODUCTION}

At present, China's economy has shifted from high-speed to high-quality, and is in the process of transforming the development mode, optimizing the economic structure, and transforming the growth momentum. Facing China's current macroeconomic operation, the poor conversion of old and new kinetic energy is an important challenge. Accelerating the transformation of old and new kinetic energy is not only the inevitable choice for solving the problem of China's economic development in the new era, but also the key to the successful transformation of the stage of economic development. In January 2018, the State Council approved the construction of a comprehensive test area for new and old kinetic energy conversion in Shandong Province. This is the first regional national development strategy approved after the 19th National Congress and the first regional development strategy with the theme of conversion of old and new kinetic energy. Shandong not only has the advantages and foundations of leading development in developed regions, but also faces the problems and confusions of the transformation and development of resource-based and heavy industrial structures. As a comprehensive test area for new and old kinetic energy conversion, Shandong is typical and representative. Therefore, it has important theoretical and practical to evaluate index system and implementation path of the new and old kinetic energy conversion, and take Shandong as an example for application analysis and compare it with the advanced areas in the east and the backward areas in the central and western regions.

Domestic scholars have constructed and analyzed the old and new kinetic energy conversion index system. From the statistical perspective, Liu Qitao[1]used the relevant data of Qingdao City as an example to make a basic analysis measure, and built an index system from six dimensions: knowledge ability, economic vitality, innovation drive, transformation and upgrading, and development effectiveness. Then adopted the quantitative measure of the index analyzed the conversion of new and old kinetic energy in Qingdao. Sun Xiumei[2] used the analytic hierarchy process and fuzzy comprehensive evaluation method to select indicators from four aspects: quality and efficiency, innovation and development, openness and environmental protection and people's livelihood, and constructed a new and old kinetic energy conversion performance evaluation index system. Then compare and analyze the effectiveness evaluation of new and old kinetic energy conversion between Shandong Province and Hebei, Zhejiang, Jiangsu and other three eastern coastal provinces. Generally speaking, there are certain limitations in the selection of performance evaluation indicators for the "new and old kinetic energy conversion" currently, and it cannot fully consider the development potential, environmental protection and other factors. This paper constructs an evaluation index system of new and old kinetic energy transformation from seven levels of development, innovation, openness, environmental protection, elements, system $\mathrm{s}$ and digits, and uses the analytic hierarchy process and entropy method to quantify the weight. Use the advanced provinces in the east and the backward provinces in the central and western as examples to apply the index system. We find that there is a gap between Shandong and the eastern advanced provinces, and based on this, propose the implementation path of the new and old kinetic energy conversion in Shandong. 
subjective evaluation on the evaluation results, the selected

2. NEW AND OLD KINETIC ENERGY CONVERSION EVALUATION INDEX SYSTEM CONSTRUCTION METHOD

\subsection{Index System Construction Principle}

In the process of establishing a new and old kinetic energy conversion effectiveness evaluation system, this paper mainly follows the following principles:1. Systematic principle: There must be a certain logical relationship between the indicators. They not only reflect the effects of the conversion of old and new kinetic energy from different aspects, but also have certain internal links between the indicators;2. Main factor principle: The indicators should be able to comprehensively reflect the main aspects of the effectiveness, and take the seven aspects as evaluation targets; 3 . Quantitative principle: In order to avoid the impact of indicators should be the relevant indicators published in the relevant bulletin and the statistical yearbook, or the data directly or indirectly calculated by relevant national data. Indicators can also reflect the qualitative content of the indicators evaluated to a certain extent.

\subsection{Indicator Selection}

On the basis of a comprehensive analysis of the effectiveness achieved by the conversion of old and new kinetic energy, following the relevant principles, through the consultation and investigation of relevant government departments, and referring to the government implementation plan related to the conversion, this paper designs an evaluation index system of conversion effectiveness. The new and old kinetic energy conversion effectiveness evaluation index system is shown in Table 1.

Table 1 New and old kinetic energy conversion effectiveness evaluation index system

\begin{tabular}{|c|c|c|c|c|}
\hline Target layer & Criteria layer & Indicator layer & coding & $\begin{array}{l}\text { Indicator } \\
\text { attribute }\end{array}$ \\
\hline \multirow{25}{*}{$\begin{array}{c}\text { New } \\
\text { and } \\
\text { old } \\
\text { kinetic energy } \\
\text { conversion } \\
\text { effectiveness } \\
\text { evaluation index } \\
\text { system }\end{array}$} & \multirow{8}{*}{$\begin{array}{c}\text { Development } \\
\text { effectiveness } \\
\text { (X1) }\end{array}$} & New economic proportion & $\mathrm{X} 11$ & Positive \\
\hline & & Full labor productivity & $\mathrm{X} 12$ & Positive \\
\hline & & The proportion of general public budget revenue in GDP & $\mathrm{X} 13$ & Positive \\
\hline & & $\begin{array}{c}\text { The proportion of the added value of strategic emerging } \\
\text { industries in GDP }\end{array}$ & $\mathrm{X} 14$ & Positive \\
\hline & & $\begin{array}{l}\text { The proportion of the added value of modern service industry } \\
\text { in GDP }\end{array}$ & $\mathrm{X} 15$ & Positive \\
\hline & & Industrial Informatization Fusion Index & $\mathrm{X} 16$ & Positive \\
\hline & & Number of top 100 most valuable brands in China & $\mathrm{X} 17$ & Positive \\
\hline & & Resident per capita disposable income & $\mathrm{X} 18$ & Positive \\
\hline & \multirow{7}{*}{$\begin{array}{l}\text { Innovation } \\
\text { development } \\
\text { (X2) }\end{array}$} & $\mathrm{R} \& \mathrm{D}$ investment as a percentage of total production & $\mathrm{X} 21$ & Positive \\
\hline & & Contribution rate of scientific and technological progress & $\mathrm{X} 22$ & Positive \\
\hline & & Number of high-tech enterprises & $\mathrm{X} 23$ & Positive \\
\hline & & R\&D staff per 10,000 people & $\mathrm{X} 24$ & Positive \\
\hline & & PCT international patent filings & $\mathrm{X} 25$ & Positive \\
\hline & & Internet plus index & $\mathrm{X} 26$ & Positive \\
\hline & & Per capita information consumption & $\mathrm{X} 27$ & Positive \\
\hline & \multirow{3}{*}{ openness (X3) } & Economic extroversion & X31 & Positive \\
\hline & & The proportion of high-tech industry exports & $\mathrm{X} 32$ & Positive \\
\hline & & $\begin{array}{l}\text { Exports to countries and regions along the "Belt and Road" } \\
\text { account for the national proportion }\end{array}$ & X33 & Positive \\
\hline & \multirow{4}{*}{$\begin{array}{c}\text { Environmental } \\
\text { protection and } \\
\text { people's } \\
\text { livelihood }(\mathrm{X} 4)\end{array}$} & 10,000 yuan regional GDP energy consumption & $\mathrm{X} 41$ & Negative \\
\hline & & Respirable particulate matter (PM2.5) concentration & X42 & Negative \\
\hline & & Clean energy generation ratio & $\mathrm{X} 43$ & Positive \\
\hline & & $\begin{array}{l}\text { The proportion of clean energy in new power generation } \\
\text { installed capacity }\end{array}$ & X44 & Positive \\
\hline & \multirow{2}{*}{$\begin{array}{c}\text { Factor } \\
\text { supply(X5) }\end{array}$} & Per capita years of education & $\mathrm{X} 51$ & Positive \\
\hline & & $\begin{array}{c}\text { The proportion of fixed assets investment in high-tech } \\
\text { industries to investment }\end{array}$ & $\mathrm{X} 52$ & Positive \\
\hline & System & The proportion of General public budget expenditure in GDP & X61 & Positive \\
\hline
\end{tabular}




\begin{tabular}{|c|c|c|c|c|}
\hline Target layer & Criteria layer & Indicator layer & coding & $\begin{array}{l}\text { Indicator } \\
\text { attribute }\end{array}$ \\
\hline & \multirow[t]{5}{*}{ supply(X6) } & The proportion of non-state-owned holding companies & $\mathrm{X} 62$ & Positive \\
\hline & & Urbanization level & X63 & Positive \\
\hline & & Marketization level & $\mathrm{X} 64$ & Positive \\
\hline & & Business Environment Index & X65 & Positive \\
\hline & & Corporate e-commerce sales ratio & $\mathrm{X} 71$ & Positive \\
\hline & \multirow{2}{*}{$\begin{array}{c}\text { Digital } \\
\text { economy }(X 7)\end{array}$} & Corporate e-commerce purchases ratio & $\mathrm{X} 72$ & Positive \\
\hline & & The proportion of online retail sales in retail sales & $\mathrm{X} 73$ & Positive \\
\hline
\end{tabular}

\subsection{Indicator evaluation method}

In the process of evaluating the effectiveness, the main calculation steps are:1.Data dimensionless processing;2.Calculate the weight of each indicator;3.Synthetic evaluation result.

\subsubsection{Data dimensionless processing}

Determine the target value of each indicator, according to the relevant standards designated by the country and the development plans of relevant cities. The relevant data is dimensionlessly processed according to the determined target value. Among them, the processing method of the positive index is the ratio of the index value to the corresponding target value; the processing method of the negative index is the ratio of the corresponding target value to the index value.

\subsubsection{Calculate the weight of each indicator}

We use information entropy to calculate weight of each indicator. First, calculate the entropy value $\mathrm{H}$ of each index by using the dimensionless data $\mathrm{x}$ obtained in step 1 . The calculation formula is:

$$
H_{j}=-\frac{1}{\ln (n)} \sum_{i=1}^{n} X_{i j} \ln \left(X_{i j}\right)
$$

Then use the result of equation (1) to calculate the degree of discrimination F. The calculation formula is

$$
F_{j}=1-F_{j} \text {. }
$$

Finally, the weight $\mathrm{w}$ of each evaluation index is calculated, and the calculation formula is:

$$
W_{j}=\frac{F_{j}}{\sum_{k=1}^{n} F_{k}}
$$

\subsubsection{Synthetic evaluation result}

By multiplying the index value after the dimensionless processing and the corresponding weight, and summing up, the evaluation results corresponding to each province and city are obtained.

\section{APPLICATION OF NEW AND OLD KINETIC ENERGY CONVERSION EVALUATION INDEX SYSTEM}

In the eastern coastal areas of China, industrial restructuring, transformation and upgrading are at the forefront of the country. In order to study the gap between Shandong Province and the eastern coastal areas, Guangdong, Jiangsu and Zhejiang were compared as advanced areas. Anhui and Henan are developing relatively fast, and the gap with Shandong is shrinking. Therefore, Anhui and Henan are compared as backward areas. Calculate the values of each indicator in Shandong, Guangdong, Jiangsu, Zhejiang, Anhui, and Henan in 2017.

Calculate the weights of the dimensionless processed data by information entropy, and obtain the weights of the indicators under each criterion and the final weights of all indicators. The weights of new and old kinetic energy conversion effectiveness evaluation index system are shown in Table 2.

Table 2 New and old kinetic energy conversion effectiveness evaluation index system weight

\begin{tabular}{cccccc}
\hline Target layer & Criteria layer & coding & Target value & Weights & Final weight \\
\hline & & X11 & 40 & 0.1287 & 0.0324 \\
New & X12 & 30 & 0.1247 & 0.0314 \\
and & & X13 & 30 & 0.1260 & 0.0317 \\
$\begin{array}{c}\text { old } \\
\text { kinetic energy } \\
\text { conversion }\end{array}$ & $\begin{array}{c}\text { Development } \\
\text { effectiveness }\end{array}$ & X14 & 20 & 0.1284 & 0.0323 \\
effectiveness & & X15 & 50 & 0.1284 & 0.0323 \\
evaluation index & & X16 & 100 & 0.1293 & 0.0326 \\
system & & X17 & 30 & 0.1081 & 0.0272 \\
& & X18 & 10 & 0.1263 & 0.0318 \\
\hline \hline
\end{tabular}




\begin{tabular}{|c|c|c|c|c|c|}
\hline Target layer & Criteria layer & coding & Target value & Weights & Final weight \\
\hline & \multirow{7}{*}{$\begin{array}{l}\text { development } \\
\text { (X2) }\end{array}$} & $\mathrm{X} 22$ & 80 & 0.1557 & 0.0325 \\
\hline & & $\mathrm{X} 23$ & 40000 & 0.1337 & 0.0280 \\
\hline & & $\mathrm{X} 24$ & 150 & 0.1503 & 0.0314 \\
\hline & & $\mathrm{X} 25$ & 30000 & 0.1007 & 0.0211 \\
\hline & & $\mathrm{X} 26$ & 100 & 0.1550 & 0.0324 \\
\hline & & $\mathrm{X} 27$ & 6000 & 0.1513 & 0.0316 \\
\hline & & X31 & 120 & 0.3142 & 0.0294 \\
\hline & \multirow[t]{2}{*}{ openness (X3) } & $\mathrm{X} 32$ & 70 & 0.3419 & 0.0320 \\
\hline & & X33 & 50 & 0.3440 & 0.0322 \\
\hline & \multirow{4}{*}{$\begin{array}{l}\text { Environmental } \\
\text { protection and } \\
\text { people's } \\
\text { livelihood }(\mathrm{X} 4)\end{array}$} & $\mathrm{X} 41$ & 0.6 & 0.2549 & 0.0325 \\
\hline & & $\mathrm{X} 42$ & 70 & 0.2529 & 0.0322 \\
\hline & & $\mathrm{X} 43$ & 50 & 0.2402 & 0.0306 \\
\hline & & $\mathrm{X} 44$ & 100 & 0.2520 & 0.0321 \\
\hline & \multirow{4}{*}{ Factor supply(X5) } & $\mathrm{X} 51$ & 15 & 0.5047 & 0.0325 \\
\hline & & $\mathrm{X} 52$ & 30 & 0.4953 & 0.0319 \\
\hline & & X61 & 30 & 0.1971 & 0.0318 \\
\hline & & $\mathrm{X} 62$ & 100 & 0.2012 & 0.0325 \\
\hline & \multirow[t]{4}{*}{ System supply(X6) } & X63 & 100 & 0.2005 & 0.0324 \\
\hline & & X64 & 100 & 0.2008 & 0.0324 \\
\hline & & X65 & 100 & 0.2004 & 0.0324 \\
\hline & & X71 & 80 & 0.3374 & 0.0311 \\
\hline & \multirow{2}{*}{$\begin{array}{c}\text { Digital } \\
\text { economy }(X 7)\end{array}$} & $\mathrm{X} 72$ & 80 & 0.3280 & 0.0302 \\
\hline & & X73 & 80 & 0.3346 & 0.0308 \\
\hline
\end{tabular}

By multiplying the dimensionlessly processed values by the corresponding index weights and summing them together, we can obtain the evaluation results of the new and old kinetic energy conversion results of six provinces in 2017. On the whole, descending order of the six provinces is Guangdong, Zhejiang, Jiangsu, Shandong, Henan, Anhui in 2017.

According to different criteria, Shandong Province has a large gap with Guangdong, Jiangsu and Zhejiang in terms of openness, environmental protection, people's livelihood development and digital economy development, even lower than that of Anhui, Henan and other backward provinces.In terms of development effectiveness, innovation and supply of factors, Shandong has a small gap with Guangdong, Jiangsu and Zhejiang, but it has no significant advantage over the backward provinces such as Anhui and Henan; In terms of system supply, Shandong is equivalent to Guangdong, Jiangsu and Zhejiang.

In terms of openness, the main reason for the low score in Shandong is that the economic outwardness is low, only $23 \%$, not only far lower than Guangdong's $76.0 \%$, but also a big gap compared with Zhejiang (49.3\%) and Jiangsu(46.5). In this regard, Shandong should expand its exports, especially the export of high-tech products, with its unique geographical location, industrial upgrading and transformation, and the Belt and Road strategy.

In terms of environmental protection and people's livelihood development, Shandong is lagging behind Guangdong, Jiangsu, and Zhejiang in the energy consumption per 10,000

yuan, PM2.5 concentration, and clean energy power generation, especially in 10,000 yuan regional GDP energy consumption. The data of Shandong was 0.5 , while the energy consumption data of Guangdong, Jiangsu and Zhejiang were all around 0.4. The 10,000 yuan regional GDP energy consumption in Shandong was higher than that of Guangdong, Jiangsu and Zhejiang by more than $20 \%$.Therefore, Shandong should rationally control the development of high-energy-consuming industries, accelerate the withdrawal of excess capacity, and improve the indicator by developing an intensive economy.

In terms of the development of the digital economy, there is a large gap between Shandong and Guangdong, Jiangsu, and Zhejiang in the proportion of online retail sales to retail sales, the proportion of corporate e-commerce sales, and the proportion of e-commerce purchases, and compared with the backward provinces, Shandong has the similar level. In this respect, Shandong should promote the development of the digital economy through sound institutional guarantees, active promotion of digitalization of local enterprises, and vigorous introduction of e-commerce enterprises.

In terms of system supply, Shandong is equivalent to Guangdong, Jiangsu, and Zhejiang. It further illustrates the achievements of Shandong as a national comprehensive test area for new and old kinetic energy conversion, and shows that the new kinetic energy has a good development environment and policy support in Shandong. The conversion 
effectiveness of new and old kinetic energy in Shandong Province and typical provinces is shown in Table 3.

Table 3 The new and old kinetic energy conversion effectiveness

\begin{tabular}{ccccccc}
\hline & Shandong & Guangdong & Jiangsu & Zhejiang & Anhui & Henan \\
\hline Comprehensive evaluation & 0.45 & 0.56 & 0.59 & 0.70 & 0.42 & 0.43 \\
Development effectiveness (X1) & 0.46 & 0.54 & 0.53 & 0.59 & 0.41 & 0.39 \\
Innovation development (X2) & 0.37 & 0.49 & 0.43 & 0.71 & 0.32 & 0.30 \\
openness (X3) & 0.33 & 0.61 & 0.54 & 0.61 & 0.35 & 0.53 \\
Environmental protection and people's & 0.49 & 0.57 & 0.79 & 0.89 & 0.53 & 0.53 \\
livelihood(X4) & 0.48 & 0.57 & 0.53 & 0.65 & 0.47 & 0.49 \\
Factor supply(X5) & 0.70 & 0.70 & 0.72 & 0.73 & 0.59 & 0.61 \\
System supply(X6) & 0.21 & 0.51 & 0.69 & 0.80 & 0.18 & 0.21 \\
Digital economy(X7) & & & & & &
\end{tabular}

\section{MAIN CONCLUSION}

Based on the principles of systemic, major and quantitative, this paper constructs an evaluation system of new and old kinetic energy conversion effects from seven perspectives. In terms of openness, environmental protection and people's livelihood development and the development of the digital economy, Shandong has a large gap with Guangdong, Jiangsu and Zhejiang, even lower than the backward provinces such as Anhui and Henan. In terms of development effectiveness, innovation development, and factor supply, the gap between Shandong and Guangdong, Jiangsu, and Zhejiang is small, but it has no significant advantage over the backward provinces. In terms of system supply, Shandong is similar to Guangdong, Jiangsu and Zhejiang. Realizing the transformation of old and new kinetic energy is a dynamic and long-term process. It is necessary to persist in deepening reform, promoting innovation, and expanding openness as the fundamental driving force for the transformation of old and new kinetic energy. Strengthen institutional design, systematic planning and coordinated promotion, and continuously stimulate the vitality and creation of the whole society. Constantly enhance the endogenous driving force of economic development, promote the quality transformation, efficiency change and dynamic change of economic development. Improve total factor productivity and promote higher quality, more efficient, fairer and more sustainable economic development.

\section{REFERENCES}

[1] Liu Yitao, Wang Lei. Research on the measurement of new and old kinetic energy conversion index [J]. China National Conditions, 2018, (09): 52-54.

[2] Sun Xiumei, Hou Shiqi. A Study of the Performance Evaluation of New and Old Kinetic Energy Conversion on the Basis of Analytic Hierarchy Process-Fuzzy Comprehensive Evaluation [J]. Journal of Shandong University of Technology(Social Sciences Edition),2019,35(01):9-14. 